\title{
Correction to: The Stored-Program Universal Computer: Did Zuse Anticipate Turing and von Neumann?
}

B. Jack Copeland and Giovanni Sommaruga

\section{Correction to:}

Chapter 3 in: G. Sommaruga, T. Strahm (eds.),

Turing's Revolution, https://doi.org/10.1007/978-3-319-22156-4_3

The chapter 'Stored-Program Universal Computer: Did Zuse Anticipate Turing and von Neumann?' was previously published non-open access. It is now available open access under a Creative Commons Attribution 4.0 International License via link.springer.com and the copyright holder has been updated to 'The Author(s)'. The book has also been updated with these changes. 